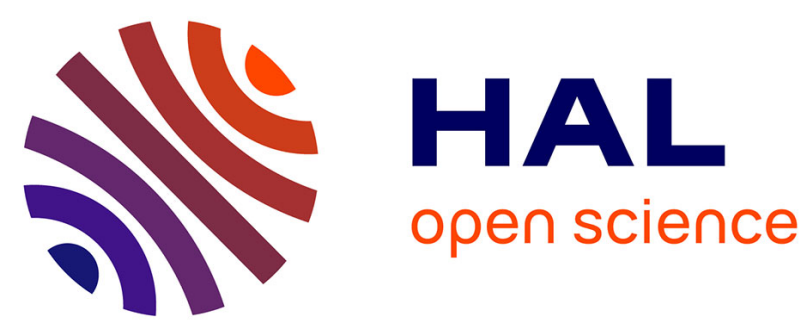

\title{
Analytical and Numerical Contributions for Winding Losses Estimation in an Integrated Magnetic Component
}

Aiman Kerim, Jean-Paul Ferrieux, James Roudet, Gérard Meunier

\section{To cite this version:}

Aiman Kerim, Jean-Paul Ferrieux, James Roudet, Gérard Meunier. Analytical and Numerical Contributions for Winding Losses Estimation in an Integrated Magnetic Component. Industry Applications Society Annual Meeting IAS 2008, Oct 2008, Edmonton, Canada. hal-00331366

\section{HAL Id: hal-00331366 https://hal.science/hal-00331366}

Submitted on 16 Oct 2008

HAL is a multi-disciplinary open access archive for the deposit and dissemination of scientific research documents, whether they are published or not. The documents may come from teaching and research institutions in France or abroad, or from public or private research centers.
L'archive ouverte pluridisciplinaire HAL, est destinée au dépôt et à la diffusion de documents scientifiques de niveau recherche, publiés ou non, émanant des établissements d'enseignement et de recherche français ou étrangers, des laboratoires publics ou privés. 


\title{
Analytical and Numerical Contributions for Winding Losses Estimation in an Integrated Magnetic Component
}

\author{
Aiman KERIM, Jean-Paul FERRIEUX, James ROUDET, Gérard MEUNIER \\ Grenoble Electrical Engineering Laboratory (G2Elab) \\ ENSIEG - BP46 \\ 38402 St MARTIN D'HERES Cedex FRANCE
}

\begin{abstract}
Analytical expressions based on the one dimensional field solution derived to compute windings losses in high frequency transformers could also be applied, under certain assumptions, to estimate losses in integrated magnetic components. To validate this approach, AC losses of two types of integrated components were analytically and numerically estimated, and the results are verified by the experimental measurement.
\end{abstract}

Index Terms - Power Electronics, integrated magnetic components, high frequency power losses, air gap effects.

\section{INTRODUCTION}

High frequency winding losses in transformers are generally estimated using the one dimensional field solution addressed in [1], [2]. Moreover, the orthogonality recognized by Ferreira allows the two terms of the high frequency losses, skin effect and proximity effect, to be analytically separated. For components with air gapped cores, many techniques [3], [4] and [5], are proposed to minimize the air gap effects and to maintain the one dimensional field solution.

Integrated magnetic components which contain capacitive and inductive components present advantages in minimizing the cost and volumes. For designers, this integration introduces some difficulties in recognizing the magnetic field distribution in the window area, and accordingly for winding losses estimation. In this situation, numerical solutions such as the finite elements programs are usually preferred to calculate the losses and to visualize magnetic field distributions. However, numerical methods are not compatible with optimization lines and become limited and expensive in time and memories for a standard PC.
This paper explores the application of the one dimensional field solution to estimate analytically winding losses in an integrated magnetic component, shown in Fig.2, under the following assumptions:

1) Air gap effect can be neglected using the techniques proposed in [3], [4] and [5], where fringing flux can still be very close to the air gap zone. Hence, the presence of a onedimensional magnetic field in the rest of the window area becomes obvious.

2) The presence of a one-dimensional magnetic field allows the primary and secondary winding losses to be estimated using Dowell [1] or Ferreira [2] methods.

3) For the center leg windings, only DC losses will be considered because of the reduced output current ripple, and the influence of the air gap negligible.

To verify this approach, two types of integrated magnetic components are designed and implemented. Windings losses are analytically estimated and compared with the results obtained by a finite elements tool. The AC resistance of the windings is measured too.

\section{SELECTED INTEGRATED MAGNETIC STRUCTURES}

Magnetic components used in the DC-DC converter shown in Fig.1 (a) could be integrated [6], [7] into one single magnetic core, Fig.1 (b). The output filtering inductance presented by the integrated structure is given as:

$L_{O}=\frac{\left(N_{C}+0.5 N_{S}\right)^{2}}{R_{C}+0.5 R_{O}}$

Where $R_{C}$ and $R_{O}$ are the reluctances of the center leg and the outer leg respectively. 


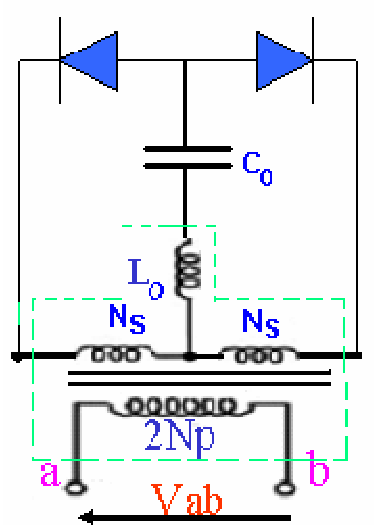

(a)

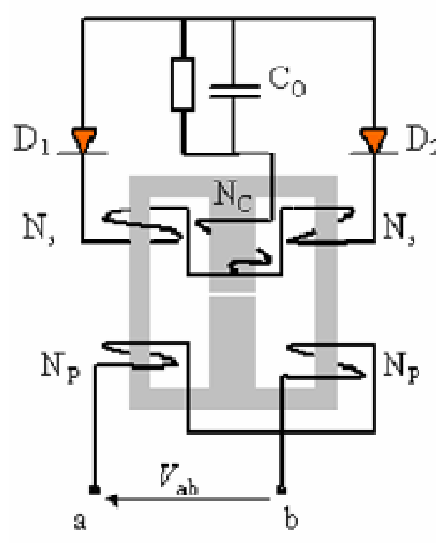

(b)
Fig. 1: Studied structure with: (a) discrete magnetic components, (b) integrated magnetic component

\section{WINDING LOSSES ESTIMATION}

\section{A. Planar integrated magnetic component}

\section{1) Analytical approach}

An integrated magnetic component, shown in Fig.2, is designed and implemented, for $1 \mathrm{~kW}, 48 \mathrm{~V}$, DC-DC converter, with an operating frequency of $150 \mathrm{kHz}$. Primary windings (20turns) are constructed using a foil of $(7 \mathrm{~mm} \times 0,2 \mathrm{~mm})$ dimensions, secondary windings (7 turns) are constructed using a foil of (2//: $9 \mathrm{~mm} \times 0,2 \mathrm{~mm})$, central windings (3 turns)with a foil of ( $2 / /: 4 \mathrm{~mm} \times 0,3 \mathrm{~mm})$. Transformer windings losses can be estimated in the $\mathrm{m}^{\text {th }}$ layer as follows:

$$
\begin{aligned}
& P_{t}=\sum_{h=1}^{n} \frac{R_{d c} \gamma_{h}}{2}\left[\left(\frac{\sinh \gamma_{h}+\sin \gamma_{h}}{\cosh \gamma_{h}-\cos \gamma_{h}}\right)+\right. \\
& \left.\left(\frac{\sinh \gamma_{h}-\sin \gamma_{h}}{\cosh \gamma_{h}+\cos \gamma_{h}}\right) \cdot(2 m-1)^{2}\right] I_{h r m s}^{2}
\end{aligned}
$$

Where: $\gamma=\lambda / \delta_{h}$

$\lambda$ is the thickness of the foil and $\delta_{h}$ is the skin depth of the corresponding harmonic.

As already indicated, for the central leg winding, only conduction losses are taken into account because of the reduced output current ripple and when one of the techniques proposed in [3], [4] and [5] is applied. Notice that no electromagnetic interaction is assumed in the window area between the central leg windings and the transformer windings

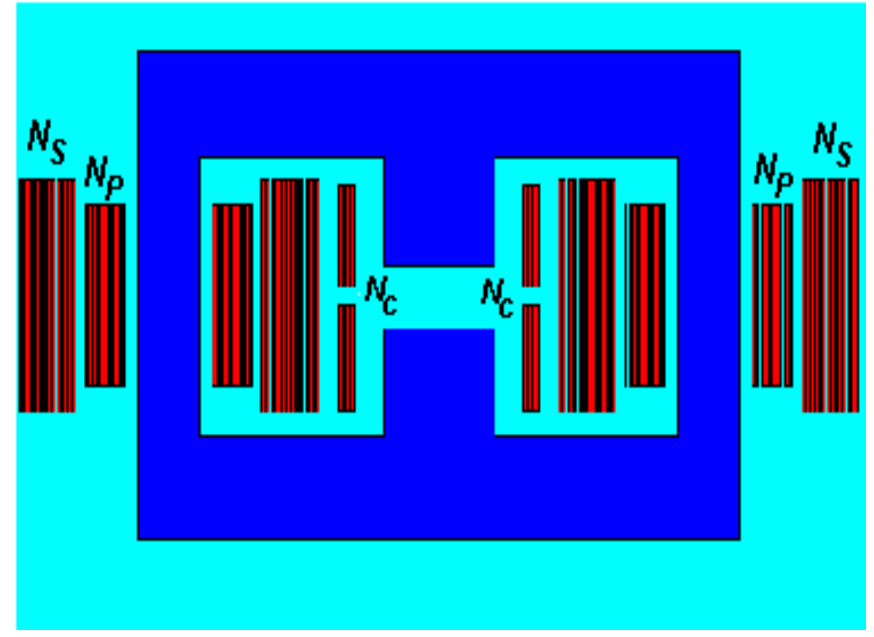

Figure.2: Planar integrated magnetic component.

So, for central windings losses we have:

$P_{c}=R_{c_{-} D C} I_{o}^{2}$

Where $R_{c_{-} D C}$ is the dc resistance of the central leg windings, and $I_{o}$ is the output dc current.

\section{2) Numerical simulation}

A numerical simulation using a 2D finite elements tool was carried out to estimate the windings losses in the structure shown in figure.3, and to visualize the magnetic field distribution in the window area, figure.4.

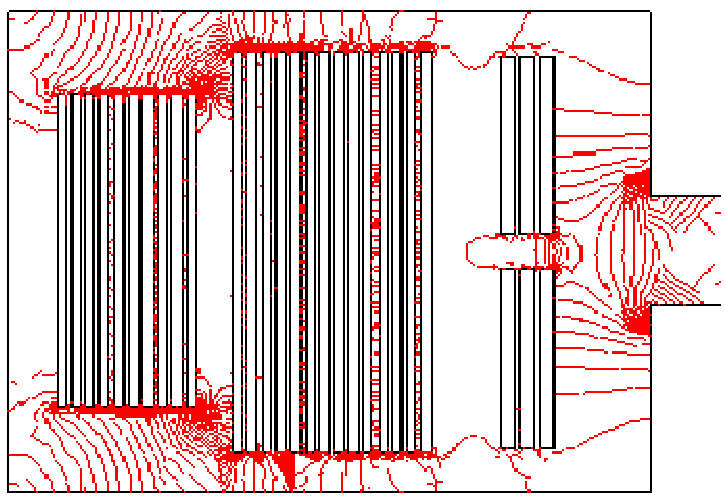

(a) 


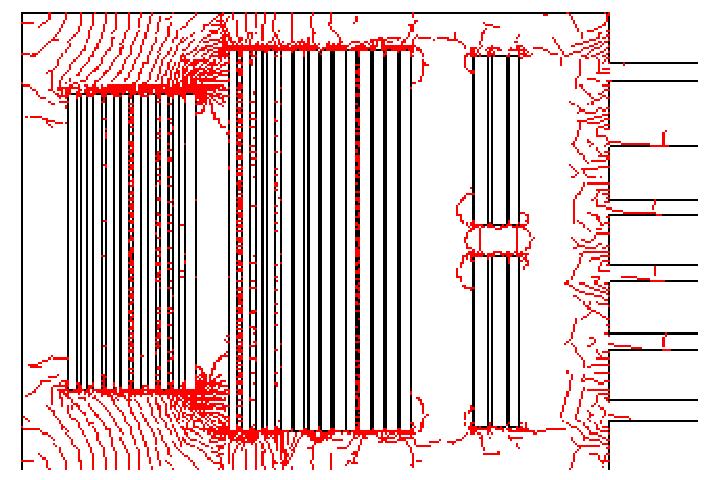

(b)

Figure.3: Magnetic field distribution in the window area: (a) with single air gap, (b) with distributed air gap.

3) Results

Windings losses are estimated in the 2D plan and represented in the Table I.

TABLE I

ESTIMATED LOSSES IN THE 2D PLAN

\begin{tabular}{|c|c|c|c|}
\hline & $\begin{array}{c}\text { Primary } \\
\text { losses } \\
\text { (W) }\end{array}$ & $\begin{array}{c}\text { Secondary } \\
\text { losses } \\
\text { (W) }\end{array}$ & $\begin{array}{c}\text { Central leg } \\
\text { winding } \\
\text { (W) }\end{array}$ \\
\hline $\begin{array}{c}\text { 2D } \\
\text { Numerical } \\
\text { estimation } \\
\text { (single air } \\
\text { gap) }\end{array}$ & 4.23 & 5.6 & 0.178 \\
\hline $\begin{array}{c}\text { 2D } \\
\text { Numerical } \\
\text { estimation } \\
\text { (distributed } \\
\text { air gap) }\end{array}$ & 4.2 & 5.56 & 0.174 \\
\hline $\begin{array}{c}\text { Analytical } \\
\text { estimation (30 } \\
\text { harmonics } \\
\text { containing DC } \\
\text { component) }\end{array}$ & 3.5 & 3.86 & 0.091 \\
\hline
\end{tabular}

As can be seen in the table I, central leg winding losses keep the same value with a single or a distributed air gap. Then, losses due to the fringing air gap field could be satisfactory neglected even with a single air gap when the output current ripple is enough reduced. Consequently, this will be considered as another advantage of this integrated magnetic structure, introduces more simplification in designing and losses estimation. In the other hand, an error was introduced in calculating secondary windings losses, where each layer of secondary is formed using two foils in parallel. Moreover, analytical estimation doesn't take into account the magnetic field distribution for the outer windings which is not totally a one-dimensional.

\section{B. Integrated magnetic component using Litz wire}

An integrated structure shown in Fig. 6 was built using Litz wires and a magnetic core type of (E55/28/21), with:

- Total primary turns $2 N_{P}=20$

- Secondary turns $N_{S}=7$

- Central leg windings $N_{C}=3$

- Number of strands in the Litz wire for primary windings $n_{S P}=250$

- Number of strands in the Litz wire for secondary and central leg windings $n_{S S}=750$

- The diameter of the strand $d_{S}=0.1 \mathrm{~mm}$

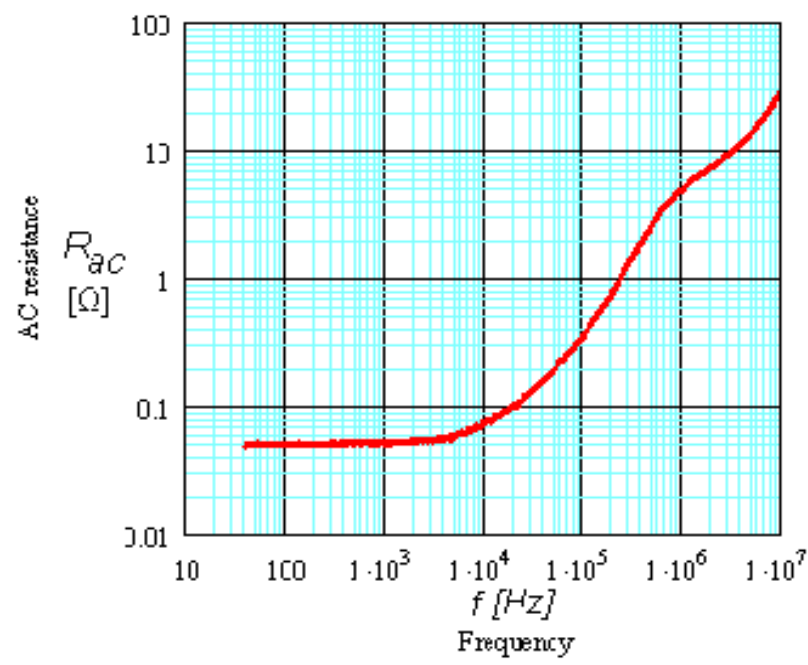

Figure.4: AC measured resistance of the transformer constructed using vertical foils and a planar core.

In neglecting the twist of strands, the homogenization conception [8], [9] and [10], allows a Litz wire exposed to an uniform transversal magnetic field $H_{e x}$ varying sinusoidal respect to time, to be dialed as a solid conductor with a complex permeability ( $\mu^{*}=\mu^{\prime}-j \mu^{\prime \prime}$ ) as shown in figure.7, where:

$\mu^{*}=\frac{1+K_{r}\left(\frac{\mu_{e r}-\mu_{d}}{\mu_{e r}+\mu_{d}}\right)}{1-K_{r}\left(\frac{\mu_{e r}-\mu_{d}}{\mu_{e r}+\mu_{d}}\right)} \cdot \mu_{d}$

And:

$\mu_{e r}=\left(\frac{J 0(\gamma)+J 2(\gamma)}{J 0(\gamma)-J 2(\gamma)}\right) \cdot \mu_{S}$

$\gamma=j^{3 / 2} \cdot \frac{\sqrt{2}}{\delta} \cdot r$ 
$k_{r}=\frac{n \cdot \pi \cdot r^{2}}{\pi \cdot R^{2}}$

and:

$n:$ Number of strands in the conductor.

$r$ : Radius of the strand in (m).

$R:$ Radius of the homogenized conductor in (m).

$\delta:$ Skin depth in (m).

$\mu_{S}$ : Magnetic permeability of the strand material.

$\mu_{d}$ : Magnetic permeability of the dielectric medium.

$j$ : Imaginary unit.

$J 0, J 2:$ Bessel functions.

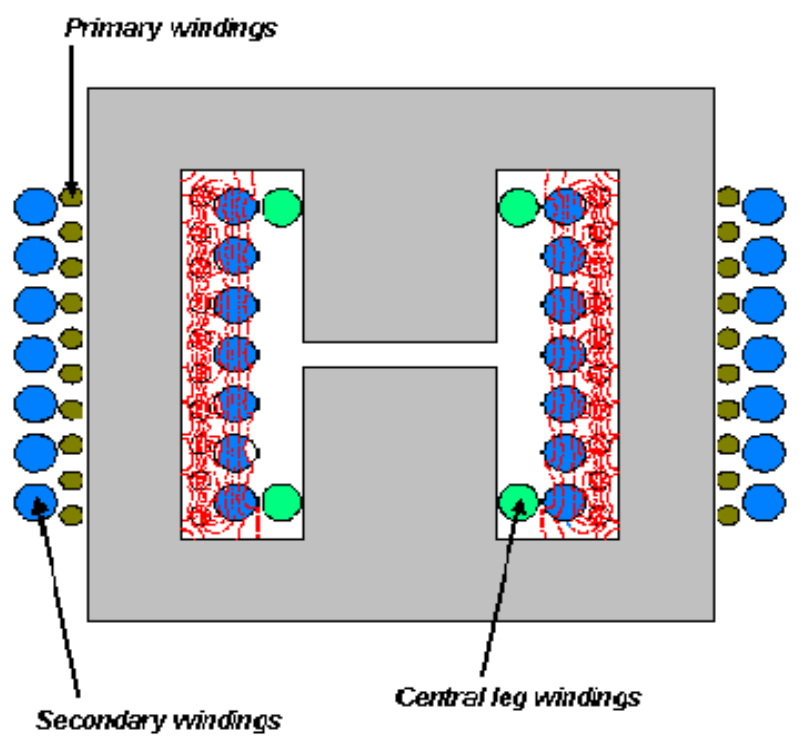

(a)

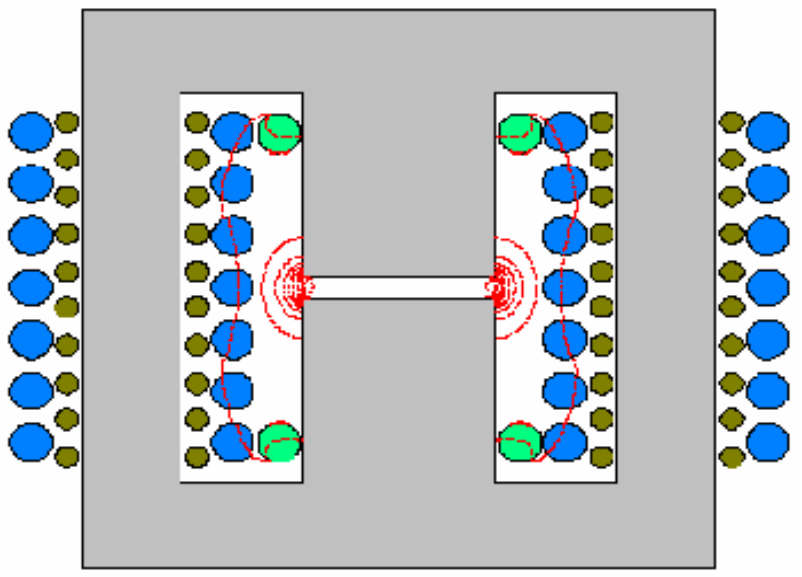

(b)

Figure.5: Magnetic field distribution in the window area when the integrated structure works as: (a) a transformer, (b) an inductor.

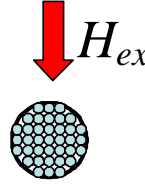

(a)

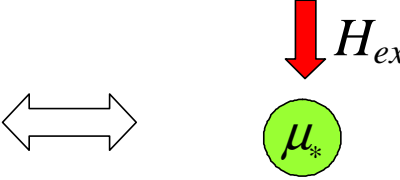

(b)
Figure.6: Principle of the Homogenization (a)Litz wire, (b) homogenized Litz wire.

1) Analytical estimation of windings losses

Litz wires losses can be estimated using classical expressions [11] and [12], derived from the exact solution of losses in a round conductor placed in a perpendicular and one dimensional field. The magnetic field distribution, shown in figure.6, visualized using the FE tool in the window area when the structure works as a transformer, justifies the application of the one dimensional field solution.

Then, Litz winding losses are given as:

$P=P_{\text {skin }}+P_{\text {prox }}$

Where:

$$
\begin{aligned}
& P_{\text {skin }}=\frac{\gamma}{2}\left(\frac{\text { ber } \gamma \cdot b e i^{\prime} \gamma-\text { bei } \gamma \cdot b e r^{\prime} \gamma}{b e r^{\prime 2} \gamma+b e i^{\prime 2} \gamma}\right) R_{d c} I_{r m s}^{2} \\
& P_{\text {prox }}=\frac{\gamma}{2} \pi \cdot n^{2}\left(\eta_{1}^{2}+\eta_{2}^{2} \cdot \frac{p}{2 \cdot \pi \cdot n_{s}}\right) \cdot\left[\frac{4\left(m^{2}-1\right)}{3}+1\right] . \\
& \left(\frac{\text { ber }_{2} \gamma \cdot b e r^{\prime} \gamma+b e i_{2} \gamma \cdot b e i^{\prime} \gamma}{b e r^{2} \gamma+b e i^{2} \gamma_{s}}\right) \cdot R_{d c} I_{r m s}^{2}
\end{aligned}
$$

And also proximity losses could be given per unit length for a homogenized Litz conductor as:

$$
P_{\text {Pr } o x}=2 f \pi^{2} R^{2} \mu^{\prime \prime} H_{e x}^{2}
$$

\section{2) Numerical Simulation of Litz windings}

In the light of the homogenization conception, magnetic components with Litz wires can be numerically simulated using finite elements tools. Proximity losses are numerically estimated in replacing Litz wires by homogenized solid conductors with a correspondent complex permeability. On the other hand, skin losses could be separately estimated (9) using the orthogonality conception [2], and then be added to proximity losses.

\section{3) Experimental measurements}

The series resistance measured for primary and secondary windings is $43 \mathrm{~m} \Omega$ measured at $150 \mathrm{kHz}$, and the DC resistance is $22.3 \mathrm{~m} \Omega$ as shown in figure 7. For $I_{r m s}=6.7 \mathrm{~A}$ of primary current, Then, primary and secondary windings losses for the first seven harmonics are given as: 


$$
\begin{aligned}
P_{\text {mesured }} & =\sum_{h=1}^{h=7} R_{a c_{-} h} I_{r m s_{-} h}^{2} \\
P_{\text {mesured }} & =3.53 \mathrm{~W}
\end{aligned}
$$

The total losses in the transformer windings, primary and secondary, are the sum of proximity losses listed in Table II, and skin losses are calculated using [9] as:

$\mathrm{d}_{\mathrm{s}}=0.1 \mathrm{~mm}$ (diameter of the strand)

Then:

$P_{\text {skin }}=1.75 \mathrm{~W}$

The Total losses are:

$$
P=P_{\text {skin }}+P_{\text {prox }} \quad P=2.5 \mathrm{~W}
$$

The difference between $\mathrm{P}_{\text {mesured }}$ and $\mathrm{P}$ can be explained, on the one hand, by the 2D modeling used for simulation and, on the other hand by the error due to the low resistance measurement.

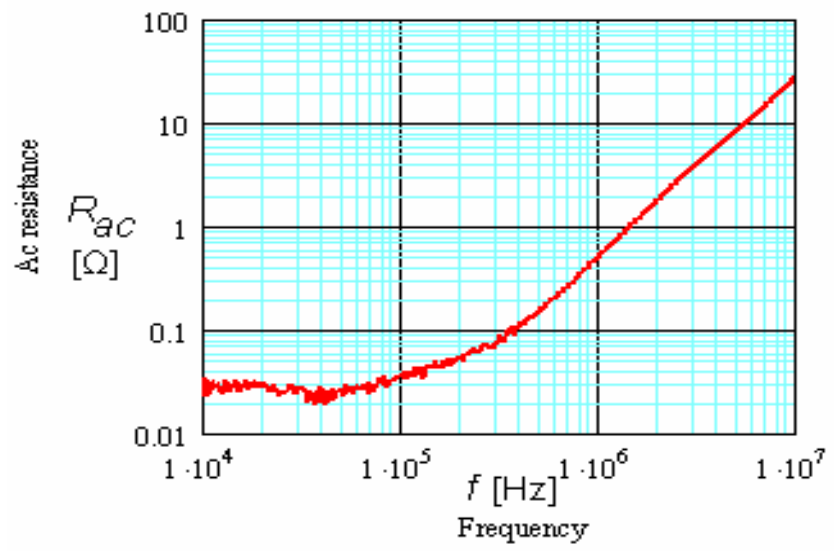

Figure 7: AC measured resistance of the transformer

\section{CONCLUSION}

Analytical formulas used to estimate winding loses in a classical transformer were extended to be applied for integrated magnetic components. The effects of magnetic fringing flux could be neglected in integrated components such as the studied structure when the output current ripple is enough reduced. Beside the analytical formulas applied to estimate litz wire windings, a method based on the homogenization was numerically and analytically applied, and experimentally verified.

\section{REFERENCES}

[1] P. L. Dowell, "Effects of Eddy Currents in Transformer Windings", IEEE Proceedings, vol. 119, pp.1387-1394, August 1966.

[2] J. A. Ferreira, "Improved Analytical Modeling of Conductive Losses in Magnetic Component," IEEE Trans. On Power Electronics, vol. 9 , pp. 127-131, January 1994.

[3] Ulrich Kirchenberger, Michael Marx and Dierk Schröder, "A Contribution to the Design Optimization of Resonant Inductors for High Power Resonant DC-DC Converters", IEEE Proceedings. IAS, vol. 1, pp.994-1001, octobre1992.

[4] M. Meinhardt, M. Duffy, T. O'Donnell, S. O'Reilly, J. Flannery and C.O. Mathuna, "New Method for Integration of Resonant Inductor and
Transformer-Design, Realization, Measurements", IEEE Proceedings. APEC, vol. 2, pp.1168-1174, March1999.

[5] J. Hu, C. R. Sullivan. Duffy, T. O’Donnell, S. O'Reilly, J. Flannery and C.O. Mathuna, "AC Resistance of Planar Power Inductors and the Quasidistributed Gap Technique”, IEEE Trans. On Power Electronics, vol. 16, pp. 127-131, July 2001.

[6] L. Yan, D. Qu and B. Lehman, "Integrated Magnetic Full Wave Converter with Flexible Output Inductor", in Proc. IEEE Applied Power Electronics Conference, vol. 18, pp. 670-678, March 2003.

[7] J. Sun, F. Webb and V. Mehrotra, "Integrated Magnetics for CurrentDoubler Rectifiers", IEEE Trans. Applied Power Electronics Conference, vol. 19, pp. 582-590, May2004.

[8] E. Matagne, "Modélisation Magnétique Macroscopique des Faisceaux de Conducteurs)," published in French.

[9] Xi Nan and Charles R. Sullivan, "An Equivalent Complex Permeability Model for Litz-Wire Windings", IEE IAS 2005, pp. 2229-2235.

[10] Dedulle J.M., Meunier G, Pierrat L, Sabonnadière J.C., "Homogenization for non linear problems applied to the modelling of transformers," ImacsTC1, Nancy, 1990

[11] Alberto Reatti and F. Grasso "Solid and Litz Wire Winding Non-linear Resistance Comparaison" in Proc. IEEE. Midwest Symp. onCircuit and System, 2000, pp.466-469.

[12] J. A. Ferreira, "Analytical Computation of AC Resistance of Round and Rectangular Litz Wire Windings" IEEE Proceedings. On Power Electronics, vol. 139, pp. 21-25, January 1992. 